\title{
Effect of boundary conditions on the evolution of lattice strains in a polycrystalline austenitic stainless steel
}

\author{
Y. Q. Wang ${ }^{1,2,3, *}$, S. Hossain ${ }^{1,4}$, S. Kabra ${ }^{5}$, S. Y. Zhang ${ }^{5}$, D. J. Smith ${ }^{1}$, and C. E. Truman ${ }^{1}$ \\ ${ }^{1}$ Department of Mechanical Engineering, University of Bristol, Bristol BS8 1TR, UK \\ ${ }^{2}$ School of Materials, The University of Manchester, Oxford Rd, Manchester M13 9PL, UK \\ ${ }^{3}$ MXIF, Research Complex at Harwell, Harwell Campus, Oxfordshire OX11 OFA, UK \\ ${ }^{4}$ Department of Aeronautical Engineering, Military Technological College, Muscat, Oman \\ ${ }^{5}$ ISIS Facility, STFC, Rutherford Appleton Laboratory, Didcot, Oxfordshire OX11 OQX, UK
}

Received: 8 December 2016

Accepted: 11 March 2017

Published online:

17 March 2017

(C) The Author(s) 2017. This article is an open access publication

\begin{abstract}
The effect of boundary conditions (constant load, constant strain and elastic follow-up) on lattice strain evolution during creep in a polycrystalline austenitic stainless steel was studied using in situ neutron diffraction at $550{ }^{\circ} \mathrm{C}$. The lattice strains were found to remain constant under constant load control. However, under constant strain and elastic follow-up control, the lattice strains relaxed the most in the elastically softest lattice plane $\{200\}$ and the least in the elastically stiffest lattice plane $\{111\}$. The intergranular stresses created between different grain families were constant during creep tests irrespective of the boundary conditions with the initial applied stresses of $250 \mathrm{MPa}$.
\end{abstract}

\section{Introduction}

The term elastic follow-up was first introduced by Robinson [1] to explain the relaxation of bolted joints due to creep. Wang et al. [2] developed a three-bar system to generate a tensile stress in a specimen (bar 1) through the introduction of a misfit $\left(\delta_{1}=\delta_{0}-\delta_{2}+2 \delta_{3}\right)$, as shown in Fig. 1a, where $\delta_{0}, \delta_{1}$, $\delta_{2}$ and $\delta_{3}$ are the total misfit, misfits in the specimen, bar 2 and bars 3, respectively. When the stress in the specimen relaxes due to creep, the stress and deformation in bars $2 / 3$ decrease/increase and tend towards their unloaded position. This results in an increase in the deformation of the specimen. This displacement redistribution is called the elastic follow-up for creep which can exist in many engineering components operating at high temperature [3]. When the specimen experiences creep while the remaining bars are elastic [4, 5], an elastic follow-up factor, $Z$, is given by.

$Z=1+\frac{1}{\beta}+\frac{1}{\gamma}$

where $\beta$ and $\gamma$ are the stiffness ratios between the specimen and the bars 2 and 3, given by $\beta=\frac{K_{2}}{K_{1}}$ and $\gamma=\frac{2 K_{3}}{K_{1}}$, where $K_{1}=\frac{A_{1} E_{1}}{L_{1}}, K_{2}=\frac{A_{2} E_{2}}{L_{2}}$ and $K_{3}=\frac{A_{3} E_{3}}{L_{3}}$ are stiffness for the specimen, bars 2 and 3, respectively. For each of the bars, $A, E$ and $L$ are the cross-sectional area, the Young's modulus and the bar length, respectively.

Address correspondence to E-mail: Yiqiang.wang@manchester.ac.uk 


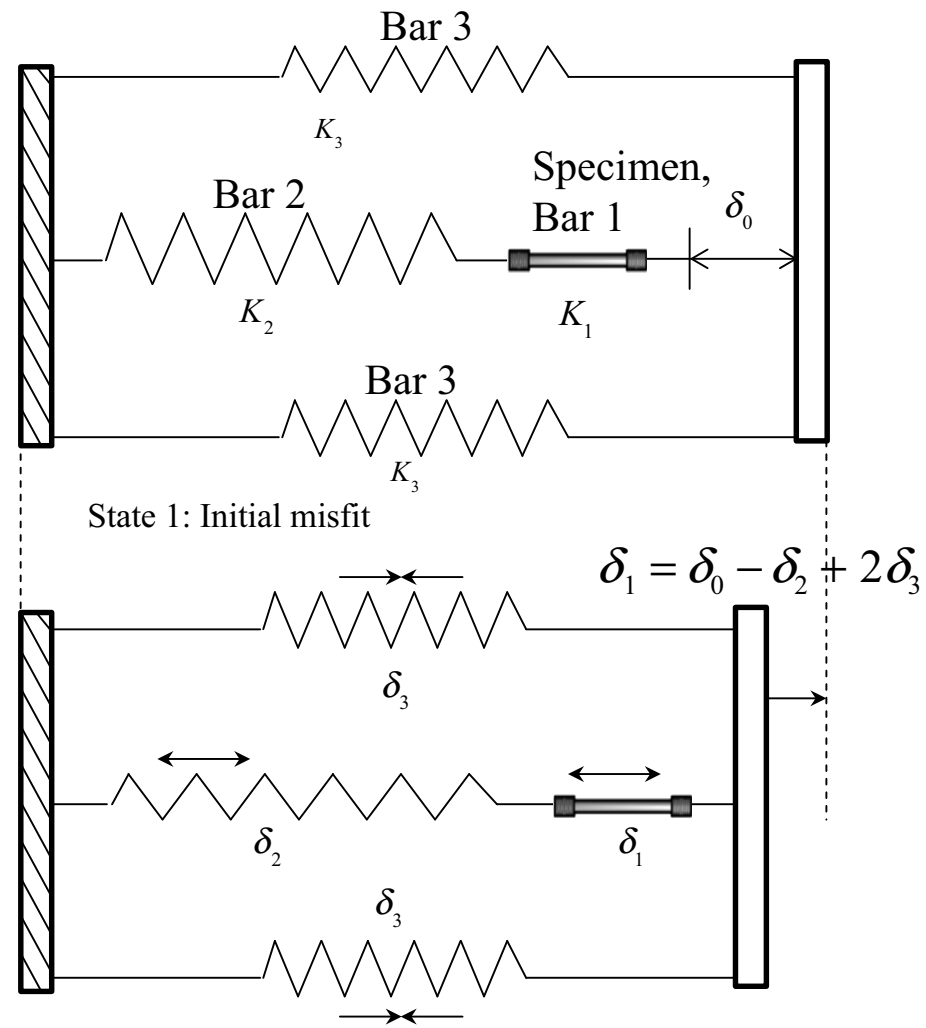

(a) State 2: Force equilibrium and creep

Figure 1 Schematic diagrams illustrating a three-bar system and the mechanical behaviour of a test specimen due to creep; a the three-bar system allows the introduction of misfit, and the system provides elastic follow-up during creep stress relaxation; $\mathbf{b}$ the

Equation 1 shows that for large stiffness ratios $\beta$ and $\gamma$ the elastic follow-up factor $Z$ tends to 1 and essentially represents constant strain control (stress relaxation). In contrast, very small stiffness ratios $\beta<<1$ and $\gamma<<1$ result in infinitely large elastic follow-up factor $(Z \rightarrow \infty)$. This represents constant load-controlled boundary condition (forward creep). The boundary conditions in between the constant strain control and the constant load control are the elastic follow-up control. This range of behaviour is illustrated in Fig. $1 \mathrm{~b}$ and shows the difference in the stress-strain curves for constant load, constant strain and elastic follow-up boundary conditions. The presence of elastic follow-up results in a slower stress relaxation rate (Fig. 1b, c) and additional strain accumulation in the specimen (Fig. 1b) when compared to a classical stress relaxation test.

It is well known that when a polycrystalline material undergoes macroscopic plastic deformation, intergranular strains or stresses can be generated
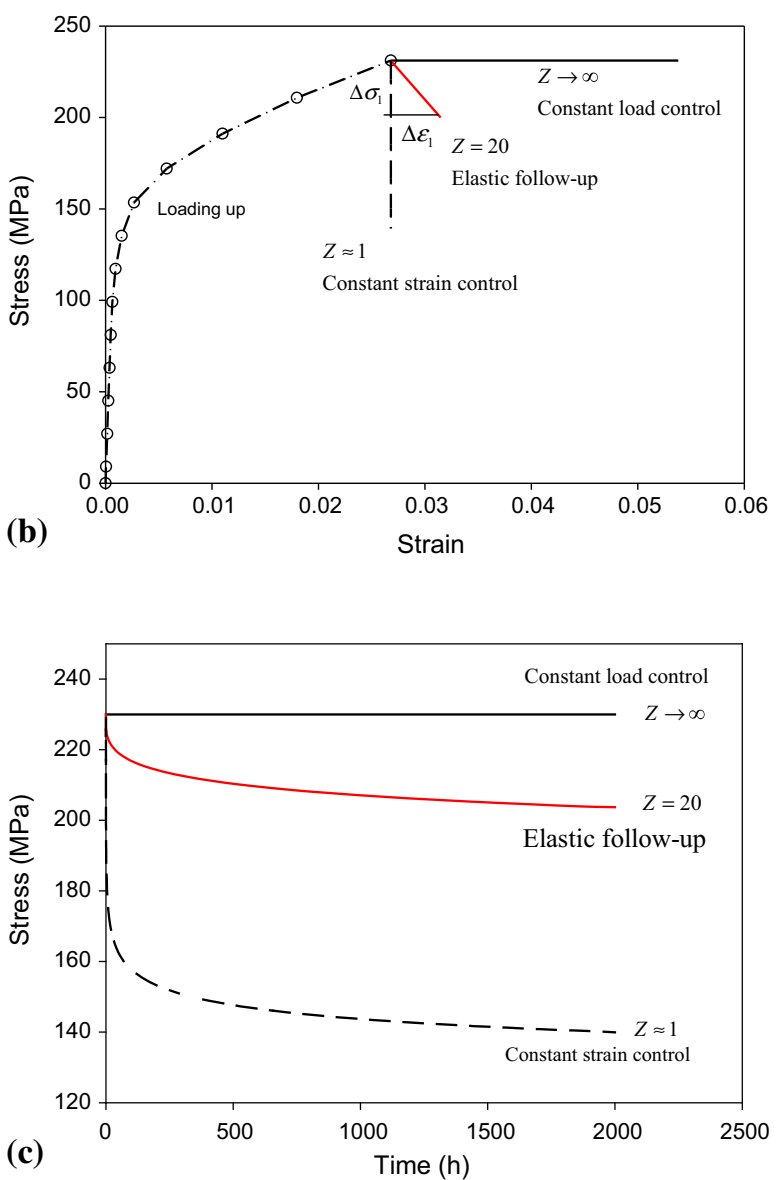

stress-strain trajectories for loading up and creep at constant load creep $(Z \rightarrow \infty)$, elastic follow-up $(1<Z<\infty)$ and stress relaxation $(Z=1)$; and $\mathbf{c}$ stress relaxation curves with elastic follow-up factor equal to 1 and 20 , respectively.

within grain families as a consequence of elasticplastic anisotropy at the grain scale [6-9]. Creep as a time-dependent plastic deformation can also generate intergranular strains/stresses in Type $316 \mathrm{H}$ austenitic stainless steel often during primary stage of the constant load creep [10-12]. This is due to creep occurring differently along different crystalline planes, thereby creating strain incompatibilities between grain families. The presence of intergranular stress can change the internal resistance and effective stress in materials which therefore change the material properties [13-16]. However, no work has been done to study the effect of elastic follow-up on creep behaviour along different crystalline orientations. The motivation for the current study arose from a need to understand and compare the evolution of intergranular strains and stresses during forward creep, stress relaxation and elastic follow-up. With such understanding, a new creep model can be built 
to predict the stress relaxation and elastic follow-up behaviour and account for the elastic follow-up into structural integrity assessment and life extension of UK's advanced gas-cooled reactors (AGRs) [17].

\section{Materials and experiment}

The material used in the present work was ex-service laboratory-aged (EXLA) Type 316H austenitic stainless steel, supplied by EDF-Energy. This $316 \mathrm{H}$ stainless steel was from header HYA 2D1/2 (cast 69431) that had been in service for approximately $65000 \mathrm{~h}$ in the temperature range of $763-803 \mathrm{~K}$, followed by exposure to $823 \mathrm{~K}$ for $21000 \mathrm{~h}$. The chemical composition of the EXLA Type $316 \mathrm{H}$ austenitic stainless steel is given in Table 1 [14].

A rig was built based on the three-bar model (Fig. 1a) which enables the in situ tracking of lattice strain evolution in $316 \mathrm{H}$ austenitic stainless steel during creep under different boundary condition. The rig was commissioned at the ENGIN-X instrument, Rutherford Appleton Laboratory (RAL), ISIS neutron facility, UK $[18,19]$. For the present experiments, two different elastic follow-up factors were obtained by using different sample dimensions. A small elastic follow-up factor $(Z \sim 1.2)$ was obtained by using a long cylindrical specimen with length $150 \mathrm{~mm}$, diameter $6 \mathrm{~mm}$ (stiffness $K_{1} 28 \mathrm{kN} \mathrm{mm}^{-1}$ ) connected to the rigid rig frame. A larger elastic follow-up factor $(Z \sim 10.5)$ was obtained by using a short specimen with length $30 \mathrm{~mm}$, diameter $7 \mathrm{~mm}$ (stiffness $K_{1} 192 \mathrm{kN} \mathrm{mm}^{-1}$ ) fitted in series to an aluminium round bar with length $250 \mathrm{~mm}$, diameter $10 \mathrm{~mm}$ (stiffness $K_{2} 19.6 \mathrm{kN} \mathrm{mm}^{-1}$ ). The elastic follow-up introduced by the remaining parts of the rig was negligible due to its large stiffness. A constant load control $(Z \rightarrow \infty)$ experiment was also conducted using a tensile rig with a radiant air furnace at ENGIN-X.

For each test, the specimen was first heated to $550{ }^{\circ} \mathrm{C}$. Load was then applied with strain rate of $0.0067 \% \mathrm{~s}^{-1}$, and the stress in the gauge length was increased in $25 \mathrm{MPa}$ steps until the stress level of $200 \mathrm{MPa}(Z=1.2), 225 \mathrm{MPa}(Z=10.5)$ and $250 \mathrm{MPa}$
$(Z \rightarrow \infty)$ was reached. For $Z=1.2$, for loading between 200 and $250 \mathrm{MPa}$, a slow loading up strain rate was used and a stress increment of about 3$5 \mathrm{MPa}$ was applied every $5 \mathrm{~min}$ in order to avoid any significant stress decrease during measurement. For constant strain and elastic follow-up tests, the stepper motor was switched off once the measured stress of $250 \mathrm{MPa}$ was achieved. The stress in the specimen decreased as the elastic strain converted to creep strain. For $Z=10.5$, the specimen was reloaded to $350 \mathrm{MPa}$ after 8-h relaxation from the initial applied stress of $256 \mathrm{MPa}$ and further relaxed for about $13 \mathrm{~h}$ at $550^{\circ} \mathrm{C}$. For the constant load creep test $(Z \rightarrow \infty)$, the applied load was maintained at $250 \mathrm{MPa}$ while the creep strain increased with time. These creep stages lasted around 8-25 h.

Elastic lattice strains along the axial direction in grain families having $\{111\},\{200\},\{220\}$ and $\{311\}$ crystallographic planes during loading up, creep and unloading were measured by neutron diffraction at approximately the middle position on the centreline of the test specimen using a $4 \times 4 \times 4 \mathrm{~mm}^{3}$ gauge volume. The acquired data were recorded over 10 and 5-min time spans during loading and creep stages, respectively. Changes in lattice spacing were used to calculate the internal strains using $\varepsilon_{h k l}=$ $\frac{d_{h k l}-d_{h k l}^{0}}{d_{h k l}^{0}}$ where $\varepsilon_{h k l}$ is the elastic lattice strain in the $\{h k l\}$ grain family, $d_{h k l}$ and $d_{h k l}^{0}$ are the sample lattice spacing and the stress-free lattice spacing at $550{ }^{\circ} \mathrm{C}$, respectively. The new designed rig only allowed the diffracted neutrons collected by detector 1 with appropriate intensity, and data collected from detector 2 with reduced intensity were not used in the experiments. The uncertainty in the measured internal strains was approximately \pm 30 microstrain. The current materials can be assumed as texture-free polycrystalline [20].

\section{Results and discussion}

A typical example of applied true stress versus the lattice strain curve during loading up can be seen in Fig. 2a. All of the crystallographic planes deformed
Table 1 Chemical composition of ex-service laboratory-aged Type $316 \mathrm{H}$

\begin{tabular}{lllllllllll}
\hline $\mathrm{C}$ & $\mathrm{Si}$ & $\mathrm{Mn}$ & $\mathrm{P}$ & $\mathrm{S}$ & $\mathrm{Cr}$ & $\mathrm{Mo}$ & $\mathrm{Ni}$ & $\mathrm{Co}$ & $\mathrm{B}$ & $\mathrm{Fe}$ \\
\hline 0.06 & 0.4 & 1.98 & 0.021 & 0.014 & 17.17 & 2.19 & 11.83 & 0.10 & 0.005 & Bal. \\
\hline
\end{tabular}


linearly at stresses lower than $120 \mathrm{MPa}$. A deviation in the linear response was observed at stresses greater than $120 \mathrm{MPa}$, which means some crystallographic planes started yielding. It should be noted that neutron diffraction always measures the elastic lattice strain. Yielded plane would not take up as much elastic strain (stress) as it would before yielding with increase in macroscopic stress. Here, as shown in Fig. 2a, the $\{220\}$ plane yielded first and resulted in the $\{200\}$ and $\{311\}$ planes taking up the elastic strain (stress) redistributed from $\{220\}$. The elastic and plastic anisotropy at each plane caused strain incompatibilities and generated intergranular stresses between the grains at different orientations. The diffraction elastic constants (DEC) for each plane were obtained by dividing the change in applied stress by the corresponding change in lattice strain for each plane during unloading and are summarised in Table 2. The elastic moduli obtained in the current study perfectly agreed with the work conducted by Daymond and Bouchard [6]. The lattice strains relaxed with the relaxation of applied stresses linearly during creep under $Z \sim 1.2$ and $Z \sim 10.5$ and act similar to unloading process, as shown in Fig. $2 b$,

Table 2 Summary of derived diffraction elastic constants (DEC) from unloading of the in situ neutron diffraction measurements at $550^{\circ} \mathrm{C}$

\begin{tabular}{lllll}
\hline Test & $E_{111}, \mathrm{GPa}$ & $E_{200}, \mathrm{GPa}$ & $E_{220}, \mathrm{GPa}$ & $E_{311}, \mathrm{GPa}$ \\
\hline $\mathrm{Z} \sim 1.2$, unloading up & 207 & 111 & 166 & 145 \\
$\mathrm{Z} \sim 10.5$, second unloading up & 183 & 107 & 162 & 126 \\
$Z \rightarrow \infty$, unloading up & 195 & 116 & 163 & 140 \\
\hline
\end{tabular}
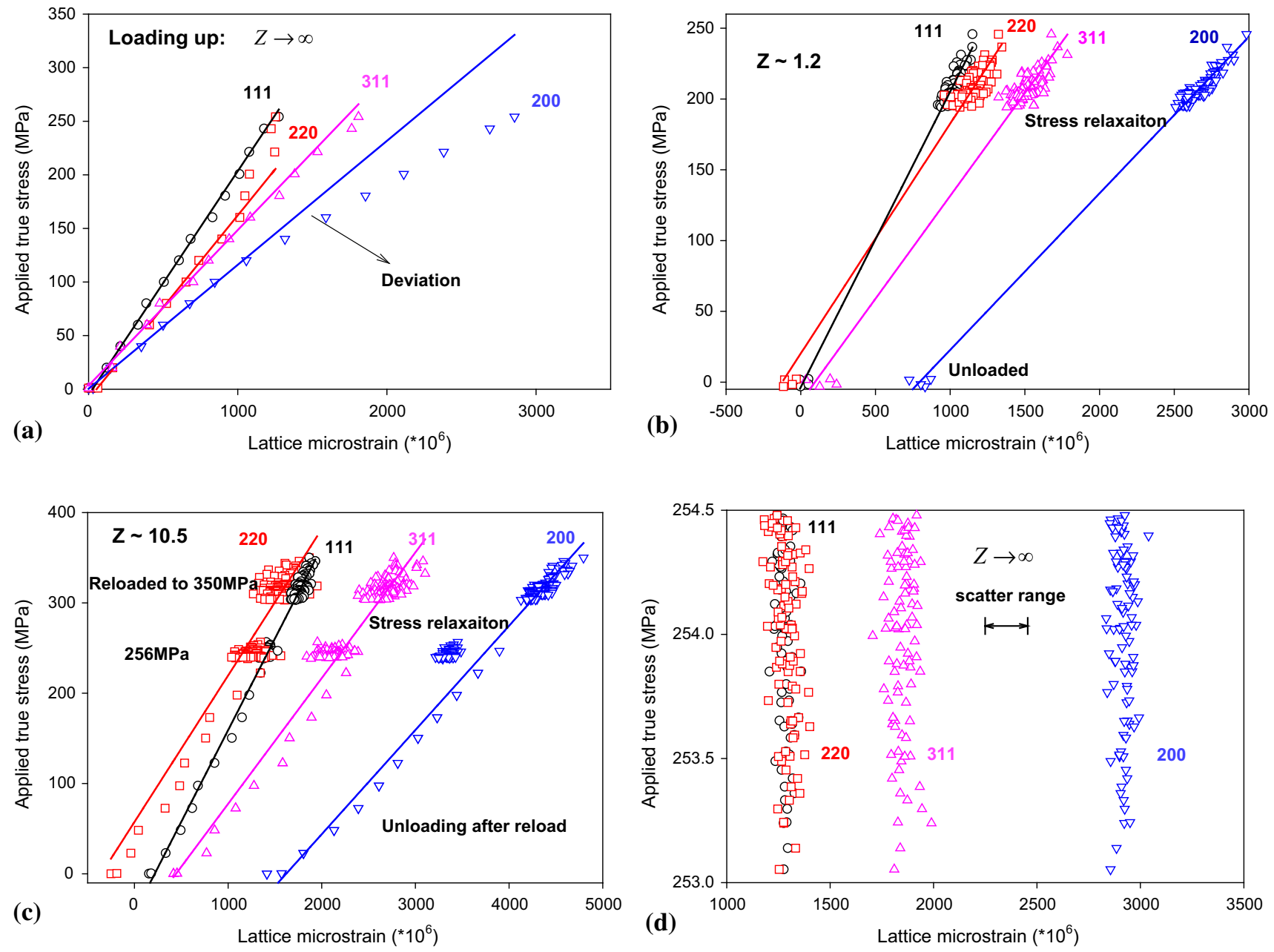

Figure 2 Neutron diffraction measured elastic lattice strains along the axial direction for $\{111\},\{200\},\{311\}$ and $\{200\}$ grain families during a loading for $Z \rightarrow \infty ; \mathbf{b}-\mathbf{c}$ creep and unloading stages for $Z \sim 1.2$ and $Z \sim 10.5$; and $\mathbf{d}$ creep stage for $Z \rightarrow \infty$. 

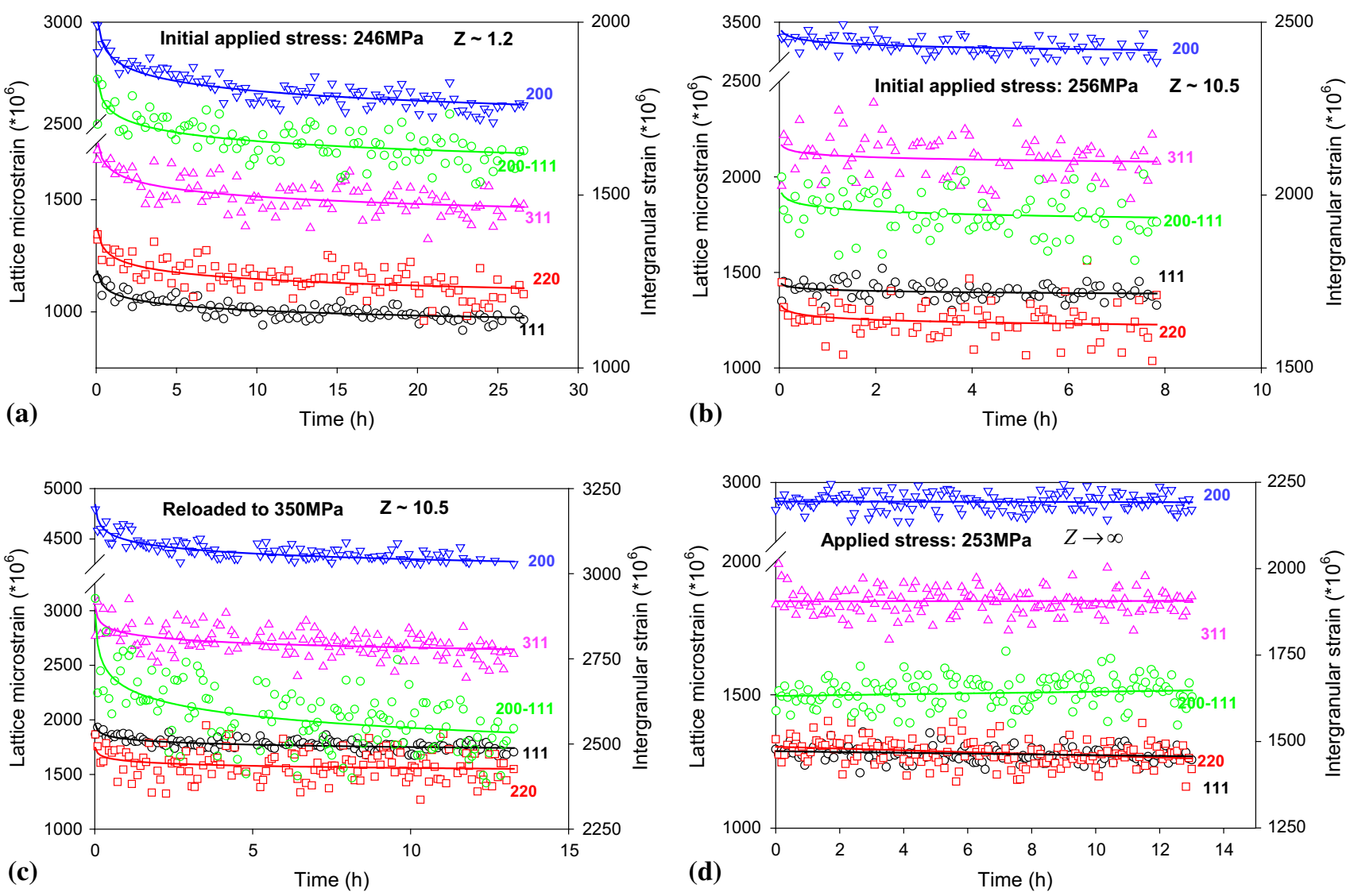

Figure 3 Elastic lattice strains and intergranular strain (between $\{200\}$ and $\{111\}$ ) evolution measured in situ during early stage of creep in Type $316 \mathrm{H}$ austenitic stainless steel at $550{ }^{\circ} \mathrm{C}$ under a $\sigma=246 \mathrm{MPa}$ for $\mathrm{Z} \sim 1 ; \mathbf{b} \sigma=256 \mathrm{MPa}, \quad \mathrm{Z} \sim 10.5 ; \mathbf{c}$

$\sigma=350 \mathrm{MPa}, \mathrm{Z} \sim 10.5$; and $\mathbf{d} \sigma=253 \mathrm{MPa}, Z \rightarrow \infty$. Green circles and green lines correspond to the secondary $Y$ axis on the right.

c. Therefore, the lattice strains were found to relax the most in the elastically softest lattice plane $\{200\}$ and the least in the elastically stiffest lattice plane $\{111\}$ due to different grain families in crystalline materials displaying elastic anisotropies. The lattice strains remained constant with some degree of scatter under constant load control (Fig. 2d).

The axial principal stress can be calculated by the strain vectors measured from neutron diffraction through the generalised Hooke's law:

$\sigma_{h k l}^{z z}=\frac{E_{h k l}}{1+v} \varepsilon_{h k l}^{z z}+\frac{E_{h k l} / v}{(1+v)(1-2 v)}\left(\varepsilon_{h k l}^{z z}+\varepsilon_{h k l}^{\theta \theta}+\varepsilon_{h k l}^{r r}\right)$

where the superscripts $z z, \theta \theta$ and $r r$ represent axial, hoop and radial principal directions in the cylindrical coordinate system, $v$ is the Poisson's ratio. In the present study, the axial stresses for each plane were calculated assuming both the hoop strain $\left(\varepsilon_{h k l}^{\theta \theta}\right)$ and the

radial strain $\left(\varepsilon_{h k l}^{r r}\right)$ were equal to $-v \varepsilon_{h k l}^{z z}$ [14]. Hence, Eq. 2 reduces to

$\sigma_{h k l}^{z z}=E_{h k l} \varepsilon_{h k l}^{z z}$

The lattice stresses were obtained by taking the product of the lattice strain and the corresponding DEC (Eq. 3).

The evolution of lattice strains and stresses with time in grain families $\{111\},\{200\},\{220\}$ and $\{311\}$ crystallographic planes during creep with $Z=1.2$, $Z=10.5$ and $Z \rightarrow \infty$ are shown in Figs. 3a-d and $4 a-$ $\mathrm{d}$. The evolution of intergranular strain and stress between $\{200\}$ and $\{111\}$ crystallographic planes is displayed using green colour in the corresponding figures with a secondary $Y$ axis on the right. All of the curves were fitted using power law. Again it shows that the lattice strains relaxed the most $(-423,-120$ and -562 microstrain) in the softest lattice plane $\{200\}$ 


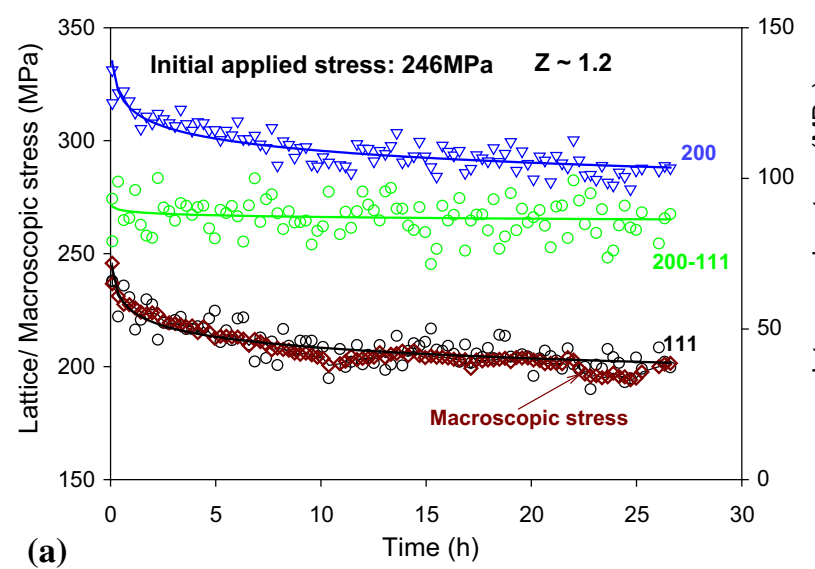

(a)

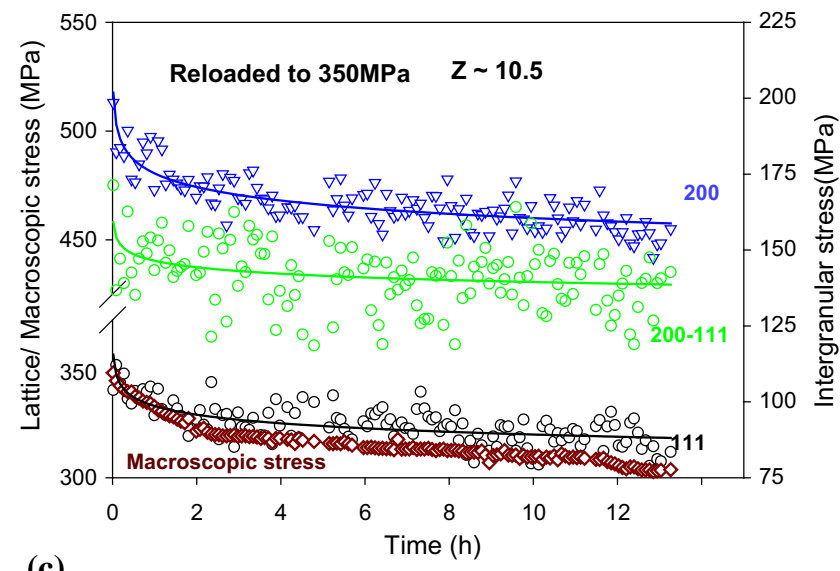

(c)

Figure 4 Lattice stresses and intergranular stress (between $\{200\}$ and $\{111\}$ ) evolution under $\mathbf{a} \sigma=246 \mathrm{MPa}$ for $\mathrm{Z} \sim 1.2 ; \mathbf{b}$ $\sigma=256 \mathrm{MPa}, \mathrm{Z} \sim 10.5$; c $\sigma=350 \mathrm{MPa}, \mathrm{Z} \sim 10.5$; and $\mathbf{d}$

and the least ( $-205,-49$, and -216 microstrain) in the hardest lattice plane $\{111\}$ under constant strain and elastic follow-up control (Fig. 3a-c). Figure $4 a-b$ shows that the presence of elastic follow-up decreased the macroscopic as well as lattice stress relaxation significantly. For the creep tests with applied or initial applied stress of $250 \mathrm{MPa}$, same amount of lattice stress had relaxed at different crystal planes and the trends agree with the macroscopic stress relaxation. However, the intergranular stress seems to have changed with time when the elastic follow-up creep test was reloaded to a higher stress of $350 \mathrm{MPa}$ (Fig. 4c). This opened an interesting future study for the current material. With a very high applied stress, the elastic follow-up might have significant effect on the evolution of intergranular stress during creep.
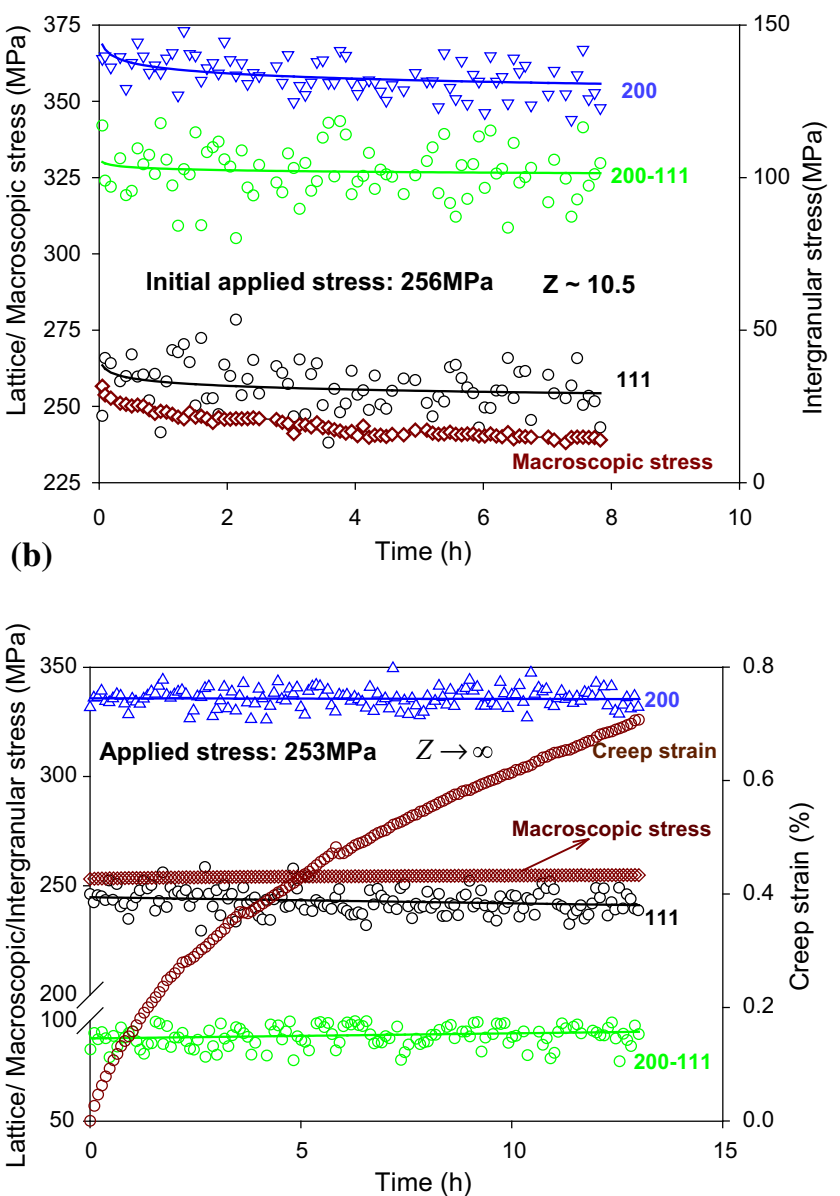

(d)

$\sigma=253 \mathrm{MPa}, Z \rightarrow \infty$. The lattice stresses were calculated using the lattice strain (Fig. 3) multiplied by the corresponding diffraction elastic constants (Table 1).

Figure $4 \mathrm{~d}$ shows that the constant load creep strain rate decreased significantly in the early stages of primary creep. However, the lattice strains and stresses, intergranular strain and stress were almost constant under constant load control (Figs. $3 \mathrm{~d}$ and $4 d)$. This is not in agreement with the previous ex situ measurements (same material and testing conditions) conducted by Chen et al. [12] which showed that the lattice strains generated in the $\{200\}$ and $\{220\}$ grain families $180 \mathrm{~h}$ of creep (creep strain $0.92 \%$ ) were approximately 440 microstrain and -275 microstrain. The discrepancies between the current and Chen's work demonstrate that the ex situ measurements might not be able to show the evolution of lattice strain precisely. The scatter of lattice strain in neutron diffraction measurements for a single sample could be as large as 300 microstrain (Fig. 3d). Factors 
included sample-to-sample differences [20], difference of plastic strains created from loading up for each sample and thermal strains/stresses introduced in each sample during air quenching [21] can also change the lattice strains in materials significantly. The current in situ constant load creep results are also different to the in situ neutron diffraction creep experiments conducted by Rao et al. [11] in spite of similar macroscopic creep strain $(\sim 0.62 \%)$ generated from similar duration (12 h) of primary creep stage. Rao et al. [11] observed that the $\{200\}$ grain family developed significant tensile creep strain (evolved from 0 to 850 microstrain) while the $\{111\}$ and $\{220\}$ developed compressive creep strains (evolved from 0 to -275 microstrain) during primary creep stage $\left(180 \mathrm{MPa}\right.$ at $\left.650{ }^{\circ} \mathrm{C}\right)$ in a solute heat-treated $316 \mathrm{H}$ austenitic stainless steel sample. This could be due to large number of carbides $\left(10^{21} \mathrm{~m}^{-3}\right)$ that can form along the grain boundaries, the slip planes and other entities within grain during the creep of the solution heat-treated sample at $650{ }^{\circ} \mathrm{C}$ [22]. The dislocation pinning therefore can change the internal resistance of each crystal plane [23], resulting in changing and redistribution of the lattice strain between grain families during creep deformation. Moreover, it is difficult to consider the change in stress-free lattice spacing due to solid solution carbon concentration [11].

\section{Conclusion}

In conclusion, a pioneering study was conducted to investigate the effect of boundary conditions on the anisotropic creep behaviour along different crystal planes in Type $316 \mathrm{H}$ austenitic stainless steel. The presence of elastic follow-up decreased the macroscopic stress and lattice stress relaxation. With the initial applied stress of approximately $250 \mathrm{MPa}$ at $550{ }^{\circ} \mathrm{C}$, the lattice strains tended to relax the most in the softest lattice plane $\{200\}$ and the least in the stiffest lattice plane $\{111\}$ to maintain lattice stress equilibrium between different grain families. Unlike previous studies, we found under constant load control that both lattice strains and stresses remained constant. Therefore, the ratio of the current applied stress to intergranular stress decreases under constant strain and elastic follow-up control while it is constant under constant load control. Nevertheless, the present study shows that the intergranular strains or stresses are not the main reason cause to the decreasing of primary creep strain rate. For elastic follow-up creep test with higher applied stress (350 MPa), both the intergranular stresses and strains were changed. This indicated that the elastic follow-up might have an effect on the evolution of intergranular strains/stresses during creep with very high applied stress. The generation of intergranular stresses under creep is different or more complicated than under monotonic loading. The evolution of lattice strain in materials during creep can change due to their precipitation strengthening, boundary conditions as well as testing temperatures and stresses.

\section{Acknowledgement}

This paper is dedicated to the late Professor David Smith. The authors would like to thank EDF Energy, for funding this work and for granting permission to publish this paper. Yiqiang Wang thanks to Dr. Sui Tan, Dr. Jianan Hu and Dr. Chen Bo for their help and advices. Experiments at the ENGIN-X, ISIS Pulsed Neutron Source were supported by a beamtime (RB1310146) allocation from the Science and Technology Facilities Council.

Open Access This article is distributed under the terms of the Creative Commons Attribution 4.0 International License (http://creativecommons.org/ licenses/by/4.0/), which permits unrestricted use, distribution, and reproduction in any medium, provided you give appropriate credit to the original author(s) and the source, provide a link to the Creative Commons license, and indicate if changes were made.

\section{References}

[1] Robinson EL (1939) The resistance to relaxation of materials at high temperature. Trans ASME 61:543-550

[2] Wang Y, Shirahatti AM, Truman CE, Smith DJ (2013) Prediction of creep crack initiation under the interaction between long range residual stress and applied load. 13rd international conference on fracture, China

[3] Ainsworth RA (2003) R5: assessment procedure for the high temperature response of structures. Br Energy Gener Ltd. 3

[4] Wang YQ, Smith DJ, Truman CE (2013) Inelastic deformation and elastic follow-up. ASME 2013 Press Vessel Pip Conf 
[5] Wang YQ, Truman CE, Smith DJ (2014) Effect of elastic follow-up on the creep stress relaxation of Type $316 \mathrm{H}$ austenitic stainless steel at $550{ }^{\circ} \mathrm{C}$. $3 \mathrm{rd}$ international ECCC creep and fracture conference

[6] Daymond MR, Bouchard PJ (2006) Elastoplastic deformation of 316 stainless steel under tensile loading at elevated temperatures. Metall Mater Trans A 37:1863-1873

[7] Lin Peng R, Odén M, Wang Y, Johansson S (2002) Intergranular strains and plastic deformation of an austenitic stainless steel. Mater Sci Eng A 334:215-222

[8] Clausen B, Lorentzen T, Leffers T (1998) Self-consistent modelling of the plastic deformation of fcc polycrystals and its implications for diffraction measurements of internal stresses. Acta Mater 46:3087-3098

[9] Mamun AA, Moat RJ, Kelleher J, Bouchard PJ (2014) Generation of intergranular strains during high temperature creep fatigue loading of $316 \mathrm{H}$ stainless steel. Mater High Temp 31:378-382

[10] Rao A, Chong KB, Bouchard PJ, Fitzpatrick ME (2011) Internal stress generation in austentic stainless steels during creep deformation. ASME Press Vessel Pip Conf 2011:215-225

[11] Rao A, Bouchard PJ, Northover SM, Fitzpatrick ME (2012) Anelasticity in austenitic stainless steel. Acta Mater 60:6851-6861

[12] Chen B, Hu JN, Flewitt PEJ, Smith DJ, Cocks ACF, Zhang SY (2014) Quantifying internal stress and internal resistance associated with thermal ageing and creep in a polycrystalline material. Acta Mater 67:207-219

[13] Chen B, Flewitt PEJ, Cocks ACF, Smith DJ (2014) A review of the changes of internal state related to high temperature creep of polycrystalline metals and alloys. Int Mater Rev 60:1-29
[14] Chen B, Hu JN, Wang YQ, Zhang SY, Van Petegem S, Cocks ACF et al (2015) Role of the misfit stress between grains in the Bauschinger effect for a polycrystalline material. Acta Mater 85:229-242

[15] Hu JN, Cocks ACF (2017) Effect of creep on the Bauschinger effect in a polycrystalline austenitic stainless steel. Scripta Mater 128:100-104

[16] Wang YQ, Spindler MW, Truman CE, Smith DJ (2016) Critical analysis of the prediction of stress relaxation from forward creep of Type $316 \mathrm{H}$ austenitic stainless steel. Mater Des 95:656-668

[17] Wang YQ, Coules HE, Truman CE, Smith DJ (2017) Effect of elastic follow-up and ageing on the creep of an austenitic stainless steel. Int J Solids Struct, Under review

[18] Santisteban J, Daymond M, James J, Edwards L (2006) ENGIN-X: a third-generation neutron strain scanner. J Appl Crystallogr 39:812-825

[19] Zhang SY, Evans A, Eren E, Chen B, Pavier MJ, Wang YQ et al (2013) ENGIN-X-instrument for materials science and engineering research. Neutron News 24:22-26

[20] Chen B, Hu JN, Wang YQ, Kabra S, Cocks ACF, Smith DJ et al (2015) Internal strains between grains during creep deformation of an austenitic stainless steel. J Mater Sci 50:5809-5816. doi:10.1007/s10853-015-9128-4

[21] Bale HA, Haboub A, MacDowell AA, Nasiatka JR, Parkinson DY, Cox BN et al (2013) Real-time quantitative imaging of failure events in materials under load at temperatures above $1,600{ }^{\circ} \mathrm{C}$. Nat Mater $12: 40-46$

[22] Rao A (2010) Creep and anelastic deformation in austenitic steels. PhD thesis submitted to The Open University, UK

[23] $\mathrm{Hu} \mathrm{JN}$, Cocks ACF (2016) A multi-scale self-consistent model describing the lattice deformation in austenitic stainless steels. Int J Solids Struct 78:21-37 